Opinion

\title{
Dynamics of Change in Human-Driven and Natural Systems: Fast Forward, Slow Motion, Same Movie? A Case Study from Plant Protection
}

\section{Didier Andrivon}

INRA, UMR1349, Institute for Genetics, Environment and Plant Protection (IGEPP), Centre de Rennes, Domaine de la Motte, BP 35327, F-35653 Le Rheu Cedex, France;

E-Mail: Didier.Andrivon@rennes.inra.fr; Tel.: +33-223-485193; Fax: +33-223-485150

Received: 3 January 2012; in revised form: 23 February 2012 / Accepted: 5 March 2012 /

Published: 14 March 2012

\begin{abstract}
Evolutionary biology and evolutionary ecology deal with change in species and ecosystems over time, and propose mechanisms to explain and predict these. In particular, they look for generic elements that will drive any organism or phylum to adaptive changes or to extinction. This paper, using examples from the field of plant protection against pests and diseases, shows that the patterns of change observed in natural and in human-driven systems are comparable, and proposes that their similarities result from the same mechanisms operating at different paces. Human-driven systems can thus be seen simply as 'fast-forward' versions of natural systems, making them tractable tools to test and predict elements from evolutionary theory. Conversely, the convergence between natural and human-driven systems opens opportunities for a more widespread use of evolutionary theory when analyzing and optimizing any human-driven system, or predicting its adaptability to changing conditions.
\end{abstract}

Keywords: evolution; selection; punctuated equilibria; complexity

\section{Introduction}

Alongside diversity, change is the key concept associated with the theory of biological evolution. Although Darwin himself insisted that evolution does not imply progress, but only means change, and thus favored 'descent with modification' over 'evolution' [1], the gradualist school rapidly equated evolution with a slow, linear, steady movement towards improvement of living organisms, i.e., 
progress along the 'great chain of beings' starting with the 'lower' organisms and culminating in Man (see Gould [2] for a thorough discussion). As convincingly shown by Larson [3], this gradualist, adaptationist view has been prevalent in neo-darwinism, the dominant paradigm in evolutionary biology for the better part of the 20th century (and continuing into the 21st). It has however been challenged over the past forty years, most notably by Stephen J. Gould and some of his colleagues, who view evolution essentially as a contingent historical process driven by chance on one side, and by rapid adaptive responses to sudden environmental variations on the other [4].

Both visions of evolution are based on the interpretation of patterns of diversity over time, related to the rhythm and mechanisms of changes observed in biological systems: among those, one can cite phyletic gradualism vs. punctuated equilibria [5], diversification and decimation as opposed to continuously increasing diversity [4], or complexity increase as an artifactual consequence of a skewed distribution of random variation within a constrained system [2]. Whether these patterns-and their underlying mechanistic explanations - apply to all, most or only some biological species and communities is still an ongoing debate. However, they have far-reaching consequences about the way evolution operates, and therefore about the possibilities and limits to manage biodiversity.

It is important to remember that ever since Rousseau, and possibly before, the impact of human activities on their environment has been regarded in the Western hemisphere as 'unnatural', and hence by essence as different from the 'natural' ecology of wild systems. Such a view implies that human-driven systems operate upon different mechanisms than 'natural' ones. This idea is still very present today, and fuels political ecology, large fields of social sciences, and sometimes everyday's vocabulary and consumer behavior (a typical example being 'organic' agriculture and food, as if the high-input, highoutput agricultural systems developed in many areas of the world, from rice paddies in the Asian South East to the large plains of North-Western Europe, were producing inorganic products from synthetic chemistry processes rather than biological products). Here, from some specific examples related to plant protection, I will however attempt to show that patterns of changes in human-driven systems are closely similar to those observed in biological systems; I also suggest that the similarities in the patterns of changes in biological and in human-driven systems are not mere coincidences, but reflect the operation of the same basic evolutionary mechanisms at a different pace and intensity. I then briefly discuss some implications and consequences for research of these similarities.

\section{Results and Discussion}

\subsection{Plant Protection: A Case Study in Human-driven Systems}

A recent estimate rates at $26-46 \%$ the actual proportion of agricultural food crops worldwide lost annually to pests and diseases, either during the vegetative period or during storage [6]. These losses are particularly high in inter-tropical regions, where both population and malnutrition are rapidly growing. More efficient crop protection strategies are therefore an urgent need to improve the feeding capacity of a world population foreseen to increase by half from the current 6.5 billion by 2050 [7]. Such strategies are based on the use of one or more methods, which basically fall into three categories: prophylactic, preventative, and curative [8]. Prophylactic methods target the restriction of pest movement and dissemination through quarantine regulations, sanitation, or destruction of primary inoculum 
sources - crop residues, volunteer plants, alternative hosts. Preventative methods such as the use of appropriate crop rotations, resistant host cultivars, or forecasting models to issue warnings about likely outbreaks aim to avoid or restrict the installation of the pest within the crop. Finally, curative methods, like the application of pesticides or dissemination of biological control agents, focus on breaking the biological cycle of an already installed pest. In this paper, I will call a 'plant protection system' any combination of methods used by a grower to manage one or several pests on a given crop.

Modern plant protection systems, which rely largely upon scientific innovations, can be viewed as prototypes of evolving systems driven by man. They have changed dramatically since the end of World War II. The massive use of highly successful pesticide families started in the 1880s with the discovery of the Bordeaux mixture by Millardet, accelerated through the 1950s-1980s and continues to this day. It fuelled a trend towards systems with high immediate efficacy, but also with potentially devastating long-term consequences for biodiversity, natural resources, consumers and even growers themselves [9]. The quest for higher yields led breeders to release highly productive cultivars with little or no resistance to pests, and growers to cultivate these over large areas, causing rapid changes in the severity of formerly minor diseases and in the genetic composition of pathogen populations [10,11]. As society goals in both developed and developing countries increasingly shift from maximum immediate productivity to sustainable food production, crop protection systems are becoming under double scrutiny: from the actors themselves (growers, processing and distribution companies), but also from the general public (consumers) and political authorities (regulators). In this context, the perception of science has drifted, to the point that some observers consider modern technological developments as an impediment towards a more sustainable, environmentally-friendly agriculture, and therefore as an obstacle to progress towards the well-being of humanity and of life as a whole. This is best exemplified during recent (and still ongoing) debates on the social acceptability and technical sustainability of GM crops engineered for pest resistance (see for instance [9,12]). Now might thus be an adequate moment to revisit the patterns of changes in crop protection systems, and to ask to which extent these patterns are consistent with those expected under the action of processes postulated to operate in biological systems.

\subsection{Are Patterns of Change in Plant Protection Systems Comparable to Biological Ones?}

\subsubsection{Pesticide Development: Punctuated Equilibria or Phyletic Gradualism?}

'Punctuated equilibria' designates a pattern of changes in taxa where long periods of stability are interrupted by rapid, dramatic speciation and phylogenic radiation events; by contrast, phyletic gradualism postulates the slow, gradual emergence of new species from every major genetic stock [5]. Punctuated equilibria and phyletic gradualism therefore result in largely different graphs when plotting species presence over time: punctuated equilibria generate trees with major jumps, few short branches and long internodes from each single node, while phyletic gradualism yields the classical 'cone of increasing diversity', similar to a bushy tree with short, frequent nodes [4]. They also suggest divergent modes of speciation: allopatric speciation would result in punctuated equilibria, whereas sympatric speciation generates a phyletic gradualism pattern [5]. 
Punctuated equilibria is a pattern very similar to the one observed for the marketing of pesticides released to control plant pests. In both cases, each radiation event (in the case of pesticides, the discovery and introduction of a new chemical family) generates a number of new taxa (species in biology, molecules in chemistry), of which only some will expand (i.e., enjoy commercial success when considering pesticides) while the rest remain rare or simply disappear (i.e., never hit the market for pesticides). The strong selection rate of molecules in pesticide screening tests (on average over 20,000 molecules tested for one finally marketed; [13]), because of the high cost of developing any commercial pesticide, probably explains the 'punctuated equilibria' pattern in pesticide development. In both biological and chemical systems, there is a phylogenic link between taxa: indeed, new pesticide groups often share parts of their chemical structure with former families, from which they are chemically derived (see for instance $[13,14]$ ). Also in both cases, the success of each taxon is related to its fitness in its main environment: for chemicals, this 'fitness' reflects the product ability to control major pathogens, a favorable price-to-return ratio, lack of undesirable side effects (e.g., low specificity to non-target organisms), but also the willingness of the firm developing a new pesticide to fill a void in its product line or to replace a non-profitable molecule by a new, profitable one-akin to a taxon filling an ecological niche in an ecosystem or displacing another taxon. The chance element is therefore a strong component of failure or success in both cases.

\subsubsection{From Genetic Resources to Cultivars: Simply Selection, or Diversification and Decimation?}

In 'The origin of species', Darwin [1] extensively described how artificial and natural selection are basically the same process acting with different time scales and intensity. While breeding new cultivars is a highly selective process, the large number of cultivars bred over time and the diversity of uses they have been bred for might have led one to expect that the cultivars of most major plant commodities would adequately mirror (or even surpass, through intra and inter-specific crosses made for breeding purposes) the diversity in the genetic resources of the corresponding botanical taxa. However, this is generally not the case. I will illustrate this with the example of potato, a major agricultural commodity in the developed and developing world to which the FAO dedicated an International Year throughout 2008. The same demonstration can certainly be made with most other agricultural crops: for instance, effective population sizes in modern improved cultivars of wheat are estimated to be only $4 \%$ of that in its ancestral species [15], explaining the dramatic loss in allelic diversity suffered by modern wheat cultivars compared to their wild relatives [16].

Over 200 species of potatoes, i.e., of tuber-bearing Solanum, exist in their original cradle, ranging from the south of the Rocky Mountains to the Chilean Andes [17]. These species constitute a highly diverse group for many traits of agricultural relevance, such as tuber yield, color, shape and quality (including starch/dry matter contents, reducing sugars contents, concentrations of undesirable glycoalkaloids, etc...), but also pest resistance (e.g., [18,19]). However, only seven of them (S. tuberosum, S. demissum, S. phureja, S. ajanhuiri, S. chaucha, S. juzepczukii and S. curtilobum) are or have been cultivated in Latin America, and only one (sub)species, Solanum tuberosum tuberosum, is grown to a significant extent in the rest of the world [17]. Within this sub-species, decimation also occurred during the domestication process. Many land races and populations coexist in farmers' fields in the Andean mountains, and farmers engaged in participatory breeding programs tend to favor such 
diversity [20]. By contrast, Salaman [21] showed that all potato cultivars grown in the British Isles up to the mid 19th century derived exclusively from two clones originally introduced in Europe in the late 16th century; their apparent phenotypic diversity simply reflects the high level of heterozygosity within a tetraploid species [22], allowing to generate a large number of new allele combinations in hybrids descending from only a few parental stocks, and even in replicas from each of these. The decimation of the genetic diversity in commercial cultivars relative to genetic resources available is further aggravated by two facts. First, only a small percentage of cultivars bred and registered for commercial uses are actually grown on significant areas. For instance, the latest figures available in France about seed multiplication of table and processing potato (excluding cultivars destined exclusively for export) show that the five most popular cultivars among the 178 multiplied occupied over $43 \%$ of the acreage [23]. Second, the average life span of successful cultivars is extraordinarily long. A good example is Bintje, bred in the 1910s by the Dutch hobby breeder L. de Vries and which was still the most widely multiplied cultivar in France in 2009/2010, occupying 1018 of the 7320 hectares of multiplication of table and processing potatoes (excluding those destined exclusively to export). The most extreme combination of these two facts occurs in the island of Jersey, where $45 \%$ of all arable farm land was occupied in 2005 by a single cultivar, International Kidney a.k.a. Jersey Royal, bred in the late 19th century and grown as the only potato cultivar in the island for over 120 years [24].

\subsubsection{Pest Management in Various Cropping Systems: A Directional Trend Towards Complexity or} Towards Simplicity?

The complexity of crop protection systems can be estimated as the number of control methods used simultaneously or sequentially against a given pest (or set of pests). The absolute minimum is one (if no control method is used, one cannot speak of a 'protection system'), while complex systems can combine a large array of methods to limit infection (e.g., sanitation, host resistance, fertility or water management, crop rotation, and a low number of pesticide applications possibly triggered by a risk forecasting model). In subsistence and in organic agriculture, where access to synthetic pesticides is banned or excessively costly, obtaining a crop worth harvesting requires a combination of several methods, each with partial efficacy. For instance, a survey of management methods of late blight (a very severe disease caused by the Oomycete Phytophthora infestans) identified by a panel of 118 organic potato growers from seven EU countries (Denmark, Norway, Germany, The Netherlands, the UK, Switzerland and France) revealed that no less than eleven different methods were used, ranging from growing resistant cultivars through lowering planting densities to spraying copper fungicides or plant strengtheners ([25]; Table 1). The sum of percentages for these 11 control measures in the survey answers amounts to 367 , indicating that on average, each of the farmers in the panel implemented 3 to 4 of them on his own crops.

Conversely, in intensive cropping systems, the availability of highly effective pesticides markedly reduces the complexity of protection systems, down to the absolute minimum of 1; indeed, most conventional growers rely exclusively on routine pesticide sprays to manage late blight (e.g., [26]). From an historical point of view, the general sequence has been to shift from subsistence, empirical systems associating prophylactic measures with unequal and partial efficacy (as do today's complex 
systems used in organic agriculture) towards high-input, low-complexity systems dominated by the massive use of pesticides [27]. In developing countries coexist subsistence farming and simplified, input-intensive systems (see for instance [28] about the case of Mexico).

Table 1. Control strategies of late blight (caused by Phytophthora infestans) identified or used by 118 organic potato growers from seven European countries. The percentages represent the proportion of farmers citing the specific control measure as the most, second most or third most important to control the disease. Source: Tamm et al., 2004 [25].

\begin{tabular}{llc}
\hline Control measure & Biological rationale & $\begin{array}{c}\text { Proportion of } \\
\text { growers citing it (\%) }\end{array}$ \\
\hline Preventative measures & & \\
\hline Use resistant cultivars & Preventing infection & 71 \\
Use high quality seed tubers & Limiting primary inoculum & 58 \\
Early planting of early cultivars & Escaping infection & 42 \\
Build high ridges & Limiting tuber infection & 38 \\
Cover waste piles & Limiting primary inoculum & 25 \\
Use low planting densities & Limiting plant-to-plant infection & 24 \\
Plant far from other potato fields & Limiting plant-to-plant infection & 10 \\
\hline Curative measures & & 45 \\
\hline Spray copper compounds & Destroying the pathogen & 23 \\
Remove infected plants or leaves & Limiting plant-to-plant infection & 16 \\
Spray plant strengtheners & Stimulating plant response to infection & 15 \\
Burning crop foliage early & Limiting plant-to-plant infection & \\
\hline
\end{tabular}

\section{Conclusions}

The patterns described here raise two main questions. The first is to assess whether the similarities between biological and human-driven systems regarding their evolutionary patterns are, or are not, indicative of functional similarities. The second is to analyze what consequences these similarities have for the management of natural and human-driven systems.

\subsection{Illusion, Analogy or Homology?}

Three possibilities might explain the similarities between patterns of changes in plant protection and in natural biological systems: (i) the patterns I described in plant protection systems are not real, but either artifacts of data processing or the result of a personal bias; (ii) these patterns are real, but only analogous to those existing in biological systems; (iii) these patterns are real and homologous of biological ones. If the first hypothesis applies, these patterns are illusions - and tell us nothing except that imagination can be misleading. If the second hypothesis is correct, they are coincidental - a case of convergent evolution where different causes lead to the same output. If the third hypothesis is correct, they can be viewed as the logical consequence of the same mechanisms acting; hence, conclusions applicable to biological systems could be also valid for plant protection systems (and possibly for other man-driven systems). 
Unfortunately, I know of no 'bullet-proof' way of deciding between the three hypotheses. However, some evidence leads me to believe the third to be correct, or at least acceptable. Darwin [1], when he demonstrated the essentially identical nature of natural and artificial selection, showed that some human-driven evolutionary processes simply magnify and accelerate the forces operating in nature. The analysis provided here extends Darwin's observation to evolutionary processes other than pure selection. Seen from this perspective, the very high consanguinity and narrow genetic base of cultivated stocks can be regarded as extreme examples of genetic drift, while man-made interspecific crosses and genetic transformation are by essence identical to natural interspecific hybridization or natural horizontal gene transfer-i.e., mechanisms operating in nature, but magnified and accelerated by man.

Developing the homology argument requires identification of the 'human system' homologs of key concepts and/or mechanisms involved in biological evolution. This is not overly difficult. To stay with the plant protection systems analyzed above, the 'fitness' of any control measure in the system might well be thought of as its economic profitability, since the most profitable practices are the ones who 'leave the most offspring' (i.e., come into wider use in the agricultural community). Inheritance can be equated to the perpetuation of use of a control method (although the process is probably more Lamarckian than Darwinian then), and the adjustments and mistakes that come with its implementation over time to mutations (i.e., copy errors of a single object). Combining control methods without changing the system itself (for instance, spraying pesticides on a partially resistant cultivar instead of a fully susceptible one) can be seen as the homolog of recombination.

The similarities between biological and cultural evolution have long been pointed out. Richard Dawkins [29] even coined a new concept (that he designated by the neologism 'meme') to describe cultural entities that replicate and are transmitted with little or no variation across generations. He made a rather strong case to support the idea that the similarities between 'memes' and 'genes' come from a basic property they share-i.e., to be 'replicators' that are subjected to variation (=mutations) and to selection. Dawkins considered the evolution of genes and memes to be analogous, probably because homology would require an identity by descent which cannot be ascertained; he nevertheless '... conjecture(d) that co-adapted meme-complexes evolve in the same kind of way as co-adapted gene-complexes'. This supports my homology argument, if only we define it as 'similarity by nature' rather than 'similarity by descent', and understand 'nature' as 'a set of intrinsic properties that make the objects sharing them subject to the same processes'.

\subsection{Consequences}

If human-driven systems work like biological systems taken to the extremes (especially in terms of time needed to achieve a given change), understanding the evolution of biological systems will provide useful hints for the assessment of immediate and delayed consequences of system management strategies led by man — the most famous example being 'Darwinian Medicine' [30]. Conversely, it also implies that we might learn from the 'fast forward experiments' that these strategies constitute to better understand, and even experiment, the long-term consequences of balanced (or unbalanced!) combinations of selection, drift and recombination, which are not directly and readily amenable to experimentation in 'slow motion' natural systems. Chemical genetics and chemical genomics, rapidly developing branches of chemistry relying on molecular interference to generate new properties or 
regulations (see for instance [31]), are excellent potential candidates to illustrate this. If correct, the view of evolution as a unifying theory has important implications for both expertise and risk assessment of human technologies, which could draw from theoretical predictions and models originally developed by ecologists and evolutionists for biological processes; it also suggests that scientists could (and probably should!) more widely use the experimental tractability of artificial, human-driven systems to feed evolutionary thinking and validate theoretical predictions. Finally, and just as importantly, it could help predict which human-driven systems are viable and which are not, given the environment in which they are to be operated, or their domains of validity.

\section{Acknowledgments}

The ideas exposed here were developed (slowly) following an initial challenge by Serge Savary to think 'outside the box' about the impact of science on plant protection. I am very indebted to him, and to several colleagues - notably Jean Sébastien Pierre, Eric Petit, and Xavier Reboud, as well as the anonymous referees who analysed the original version of this paper- for useful discussions and critical comments. This article, being an 'Opinion', reflects the views of the author, and not necessarily those of the colleagues who commented on it. It is respectfully dedicated to the memory of Stephen Jay Gould, as an attempt to follow his unorthodox, but highly fruitful habit of putting apparently unrelated facts into a common perspective.

\section{Conflict of Interest}

The author declares no conflict of interest.

\section{References}

1. Darwin, C. The Origin of Species by Means of Natural Selection or the Preservation of Favoured Races in the Struggle for Life, 1st ed.; John Murray: London, UK, 1859.

2. Gould S.J. Full House; Harmony Books: New York, NY, USA, 1996.

3. Larson, E.J. Evolution-The Remarkable History of a Scientific Theory; Modern Library: New York, NY, USA, 2004.

4. Gould, S.J. Wonderful Life; W.W. Norton \& Co.: New York, NY, USA, 1989.

5. Eldredge, N.; Gould. S.J. Punctuated Equilibria: An Alternative to Phyletic Gradualism. In Models in Palaeobiology; Schopf, T.J.M., Ed.; Freeman, Cooper and Co.: San Francisco, CA, USA, 1972; pp. 82-115.

6. Oerke, E.C. Crop losses to pests. J. Agric. Sci. 2006, 144, 31-43.

7. United Nations. World population to reach 10 billion by 2100 if fertility in all countries converges to replacement level. Press Release on the 2010 Revision of the World Population Prospects, 2011. Available online: http://esa.un.org/unpd/wpp/Other-Information/Press_Release_WPP2010.pdf (accessed on 30 December 2011).

8. Agrios, G.N. Plant Pathology, 5th ed.; Elsevier Academic Press: Amsterdam, The Netherlands, 2005. 
9. Aubertot, J.N.; Barbier, M.; Carpentier, A.; Grill, J.J.; Guichard, L.; Lucas, P.; Savary, S.; Savini, I.; Voltz, M. Pesticides, Agriculture et Environnement: Réduire L'utilisation des Pesticides et Limiter Leurs Impacts Environnementaux; Quae Editions: Paris, France, 2011; 60 page English summary. Available online: http://www.international.inra.fr/research/some_examples/pesticides_agriculture and the environment (accessed on 30 December 2011).

10. Marshall, D.R. The advantages and hazards of genetic homogeneity. Proc. N. Y. Acad. Sci. 1977, 287, 1-20.

11. McDonald, B.A.; Linde, C. The population genetics of plant pathogens and breeding strategies for durable resistance. Euphytica 2002, 124, 163-180.

12. Miller, H.I.; Morandini, P.; Ammann. K. Is biotechnology a victim of anti-science bias in scientific journals? Trends Biotechnol. 2008, 26, 122-125.

13. Plimmer, J.R. Chemistry of Pesticides. In Principles of Pesticide Toxicology Handbook; Krieger, R., Ed.; Academic Press: San Diego, CA, USA, 2001; pp. 95-107.

14. Baldwin, B.C. Potential Targets for the Selective Inhibition of Fungal Growth. In Mode of Action of Antifungal Agents; Trinci, A.P.J., Ryley, J.F., Eds.; Cambridge University Press: Cambridge, UK, 1984; pp. 43-62.

15. Thuillet, A.C.; Bataillon, T.; Poirier, S.; Santoni, S.; David, J.L. Estimation of long-term effective population sizes through the history of durum wheat using microsatellite data. Genetics $\mathbf{2 0 0 5}$, $169,1589-1599$.

16. Roussel, V.; Koenig, J.; Beckert, M.; Balfourier, F. Molecular diversity in French bread wheat accessions related to temporal trends and breeding programmes. Theor. Appl. Genet. 2004, 108, 920-930.

17. Hawkes, J.G. The Potato: Evolution, Biodiversity and Genetic Resource; Belhaven Press: London, UK, 1990.

18. Hawkes, J.G. Significance of wild species and primitive forms for potato breeding. Euphytica 1958, 7, 257-270.

19. Spooner, D.M.; Bamberg, J.B. Potato genetic resources: Sources of resistance and systematics. Am. Potato J. 1994, 71, 325-337.

20. Danial, D.; Parlevliet, J.; Almekinders, C.; Thiele, G. Farmers' participation and breeding for durable disease resistance in the Andean region. Euphytica 2007, 153, 385-396.

21. Salaman, R.N. The History and Social Influence of the Potato, Revised impression with a new introduction; Hawkes, J.G., Ed.; Cambridge University Press: Cambridge, UK, 1985.

22. Simko, I.; Haynes, K.G.; Jones, R.W. Assessment of linkage disequilibrium in potato genome with single nucleotide polymorphism markers. Genetics 2006, 173, 2237-2245.

23. Plant de pomme de terre français. Production par variété, campagne 2009-2010. Available online: http://www.plantdepommedeterre.org/pages/prod.htm (accessed on 30 December 2011).

24. Keefe, H. Case study: Jersey Royal potatoes (PDO). University of Alicante, Alicante, Spain, 2006. Available online: http://ecologic.eu/download/projekte/1800-1849/1802/jersey_royal_potatoes.pdf (accessed on 30 December 2011). 
25. Tamm, L.; Smit, A.B.; Hospers, M.; Janssens, S.R.M.; Buurma, J.S.; Mølgaard, J.P.; Laerke, P.E.; Hansen, H.H.; Hermans, A.; Bødker, L.; et al. Assessment of the socio-economic impact of late blight and state of the art management in European organic potato production systems. Research Institute for Organic Agriculture /FiBL: Frick, Switzerland, 2004.

26. Johnson, D.A.; Cummings, T.F.; Hamm, P.B. Cost of fungicides used to manage potato late blight in the Columbia Basin: 1996 to 1998. Plant Dis. 2000, 84, 399-402.

27. Evans, D.A. How Can Technology Feed the World Safely and Sustainably? In Pesticide Chemistry and Bioscience: The Food-Environment Challenge; Brooks, G.T., Roberts, T.R., Eds.; Royal Society of Chemistry: Cambridge, UK, 1999; pp. 3-24.

28. Flier, W.G.; Grunwald, N.J.; Kroon, L.P.N.M.; Sturbaum, A.K.; van den Bosch, T.B.M.; Garay-Serrano, E.; Lozoya-Saldana, H.; Fry, W.E.; Turkensteen, L.J. The population structure of Phytophthora infestans from the Toluca Valley of central Mexico suggests genetic differentiation between populations from cultivated potato and wild Solanum spp. Phytopathology 2003, 93, 382-390.

29. Dawkins, R. The Selfish Gene; Chapter 11; New ed.; Oxford University Press: Oxford, UK, 1989.

30. Nesse, R.M.; Bergstrom, C.T.; Ellison, P.T.; Flier, J.S.; Gluckman, P.; Govindaraju, D.R.; Niethammer, D.; Omenn, G.S.; Perlman, R.L.; Schwarz, M.D.; et al. Making evolutionary biology a basic science for medicine. Proc. Natl. Acad. Sci. USA 2010, 107, 1800-1807.

31. Xheng, X.F.S. Chemical Genetics and Chemical Genomics; Lavoisier: Paris, France, 2005.

(C) 2012 by the author; licensee MDPI, Basel, Switzerland. This article is an open access article distributed under the terms and conditions of the Creative Commons Attribution license (http://creativecommons.org/licenses/by/3.0/). 